\title{
DNA ANALYSIS OF A PATIENT WITH TWO DIFFERENT MARKER CHROMOSOMES USING Y-SPECIFIC DNA PROBES
}

\author{
Takashi Tamura, ${ }^{1,2}$ Yoshikazu Kuroki ${ }^{3}$ Shigeo Nagafuchi, ${ }^{1}$ \\ Seizo SuWA, ${ }^{4}$ Yutaka NaKahori, ${ }^{1}$ Kazumitsu Terashima, ${ }^{5}$ \\ Toshiyuki Furusho, ${ }^{2}$ and Yasuo NAKAGOME ${ }^{1}$ \\ 1 Department of Congenital Abnormalities Research, \\ National Children's Medical Research Center, Setagaya-ku, Tokyo 154, Japan \\ ${ }^{2}$ Department of Clinical Genetics, Kyorin University School of Health Sciences, \\ Mitaka, Tokyo 192, Japan \\ ${ }^{3}$ Division of Medical Genetics, ${ }^{4}$ Department of Endocrinology and \\ ${ }^{5}$ Department of Urology, Kanagawa Children's Medical Center, \\ Minami-ku, Yokohama 232, Japan
}

Summary A female patient with unilateral gonadal dysgenesis was a mosaic for three cell lines, $45, \mathrm{X} / 46, \mathrm{X},+\operatorname{marl} / 46, \mathrm{X},+$ marII, including two different marker chromosomes. DNA analysis using $17 \mathrm{Y}$-specific DNA probes revealed that each marker consists of different segments of the $\mathrm{Y}$ chromosome.

Key Words Y chromosome, marker chromosome

\section{INTRODUCTION}

It is difficult to identify the origin of small marker chromosomes using cytological techniques as many marker chromosomes fail to show characteristic banding patterns.

In the present report, we used $17 \mathrm{Y}$-specific DNA probes to analyze DNA from a female patient with clitoral enlargement who had two different marker chromosomes. Each of the markers consists of a part of the $\mathrm{Y}$ chromosome.

\section{CASE REPORT}

A newborn girl was investigated, because of clitoral hypertrophy and bilateral inguinal hernias. The presence of vagina and uterus was established by the urethrography. Clitoroplasty and surgery to correct the bilateral inguinal hernias were

Received March 2, 1991; revised version received May 1, 1991; Accepted May 7, 1991. 
performed. The right hernial content was proven to be testis and was excised. A uterus and a possible streak gonad were found in the left inguinal hernia and a small part of the latter was removed. At eight months of age, no development delay was apparent. Clinical features were normal except for those noted above.

Laboratory analyses revealed: blood testosterone $0.9 \mathrm{ng} / \mathrm{ml}$; elevated LH (282 $\mathrm{ng} / \mathrm{ml})$ and FSH $(655 \mathrm{ng} / \mathrm{ml})$, normal values being $0-1,4-63$ and $0-150$ respectively; and normal adrenal function.

\section{CYTOGENETIC STUDIES}

A $45, \mathrm{X} / 46, \mathrm{X},+\operatorname{marl} / 46, \mathrm{X},+$ marlI karyotype was observed in cells cultured from peripheral blood leukocytes (Fig. 1). Out of 31 cells karyotyped, five were 45,X, 23 had mar I and three had mar II. Both markers I and II were Q-negative. The former was a small ring chromosome (Fig. 1a). The latter was a G-sized chromosome. In some of mitotic spreads marker II appeared to be dicentric (Fig. 1b). Additional material for a C-band study was not available.

\section{DNA STUDIES}

A total of 17 Y-specific DNA probes were used. Ten of them: 87-4(AMGL); 87-6(DYS135); 87-7(DYS130); 87-17(DYS131); 87-19(DYS132); 87-24(DYS133); 87-26(DYS139); 87-27(DXYS73Y); 87-28(DYS140), and 87-31(DYS134), were cloned by Nakahori et al. (1991). The pHY10 probe detects the repetitive DNA family DYZ1 in the Q-positive region (interval 7) of the Y chromosome (Nakahori

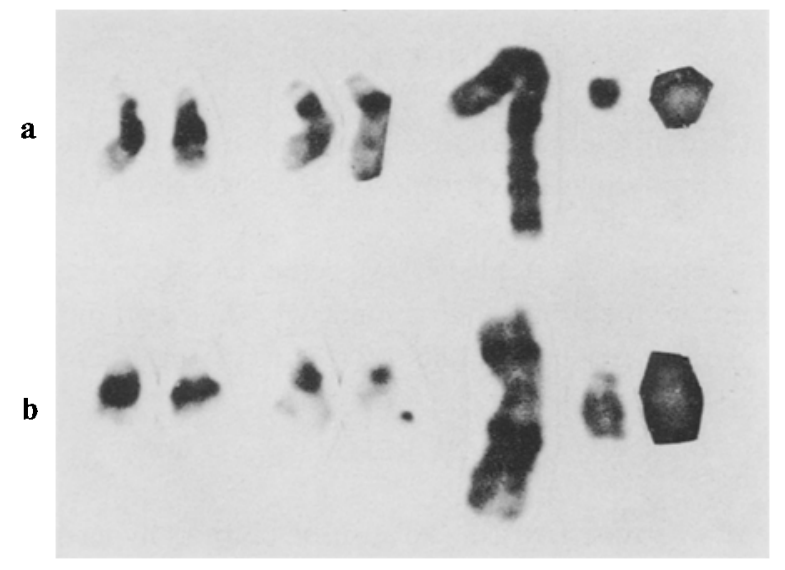

Fig. 1. Two marker chromosomes in the patient. Top: Partial karyotype of a cell with marker I. From left; $G$ stained chromosome pairs, numbers 21 and 22, an $X$ chromosome and marker I. At the far right, the Q-stained marker is shown. Bottom: As above except that marker II instead of marker I is shown. 


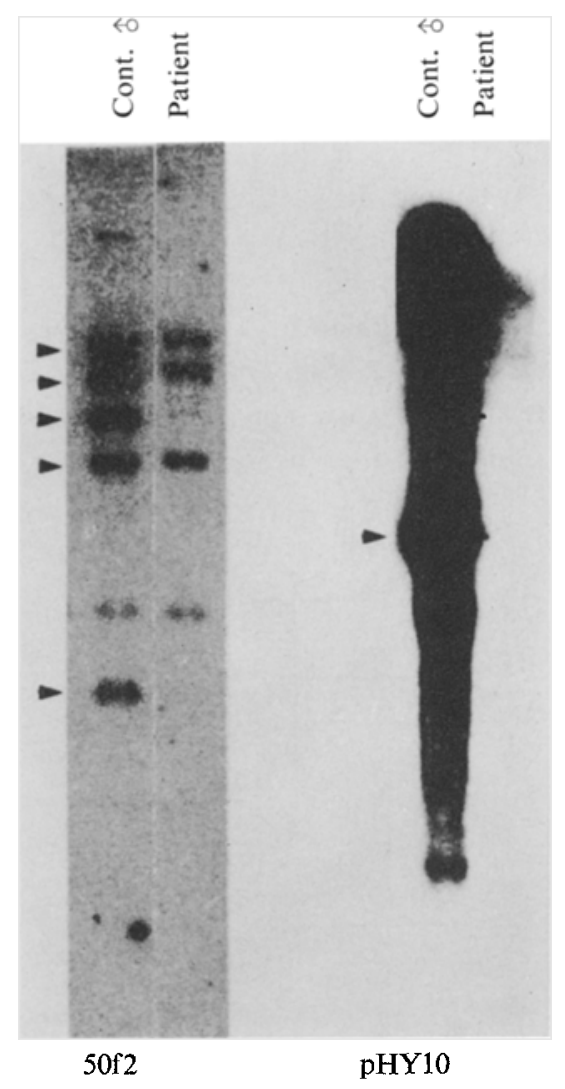

Fig. 2. Examples of Southern analysis. For each probe, both control male DNA and that of the patient are shown. In the 50f 2 blot (left), arrow heads indicate loci A to $\mathrm{E}$ (from the top). Loci A, B and D showed decreased but distinct signals $(++$ in Fig. 3). The band corresponding to locus $\mathrm{C}$ of $50 \mathrm{f} 2$ barely distinguishable. The band corresponding to $50 \mathrm{f} 2$ locus $\mathrm{E}$ is not detectable under our standard hybridization conditions and was observed only after prolonged exposure (not shown). The patient is pHY10 negative (right).

et al., 1986). The remaining six probes were gifts from Dr. J. Weissenbach (probes 47z, 52d, 50f2, 12f3, and 49f; Vergnaud et al., 1986) and a gift from Dr. D. C. Page (probe pDP1007(ZFY); Page et al., 1987). Probe $50 \mathrm{f} 2$ detects five different loci (50f $2 \mathrm{~A}$ to $50 \mathrm{f} 2 \mathrm{E}$ ) on the $\mathrm{Y}$ chromosome (see Fig. 2). Probe 52d detects three different loci: 52dA (Yq11); 52dB (Yp) and 52dC (Yp). Probe 87-17 (DYS131) detects two different sites DYS131A (Yq) and DYS131B (Yp). The 17Y-specific DNA probes had already been mapped on the $Y$ chromosome and were found to detect a total of 23 loci (Nakahori et al., 1991).

DNA was isolated from peripheral leukocytes by the standard technique (Maniatis et al., 1982). Probes pDP1007, 47z, 52d, 87-4, 87-7, 87-19, 87-26, and 
87-27 were used to probe Southern blots of TaqI digested patient DNA. The pHY10 probe was used in combination with StuI (Nakahori et al., 1989). The remaining probes were used with $E c o$ RI.

Differences were observed between the patient DNA patterns of probes from separate regions of the $\mathrm{Y}$ chromosome. Firstly, the Y-specific repeated sequence DYZ1 identified by pHY10 was absent in the patient (Fig. 2). Second, the intensities of the signals produced, when the other probes were hybridized to the patient DNA, varied according to the location of those probes on the $\mathrm{Y}$ chromosome. Medium signal intensities were observed for probes between pDP1007 in interval 1 and 87-19 in interval 5-6. Low signal intensities were observed for probes between $87-6$ and $49 \mathrm{f}$ in interval 5-6. The results of the DNA analysis are summarized in Fig. 3.

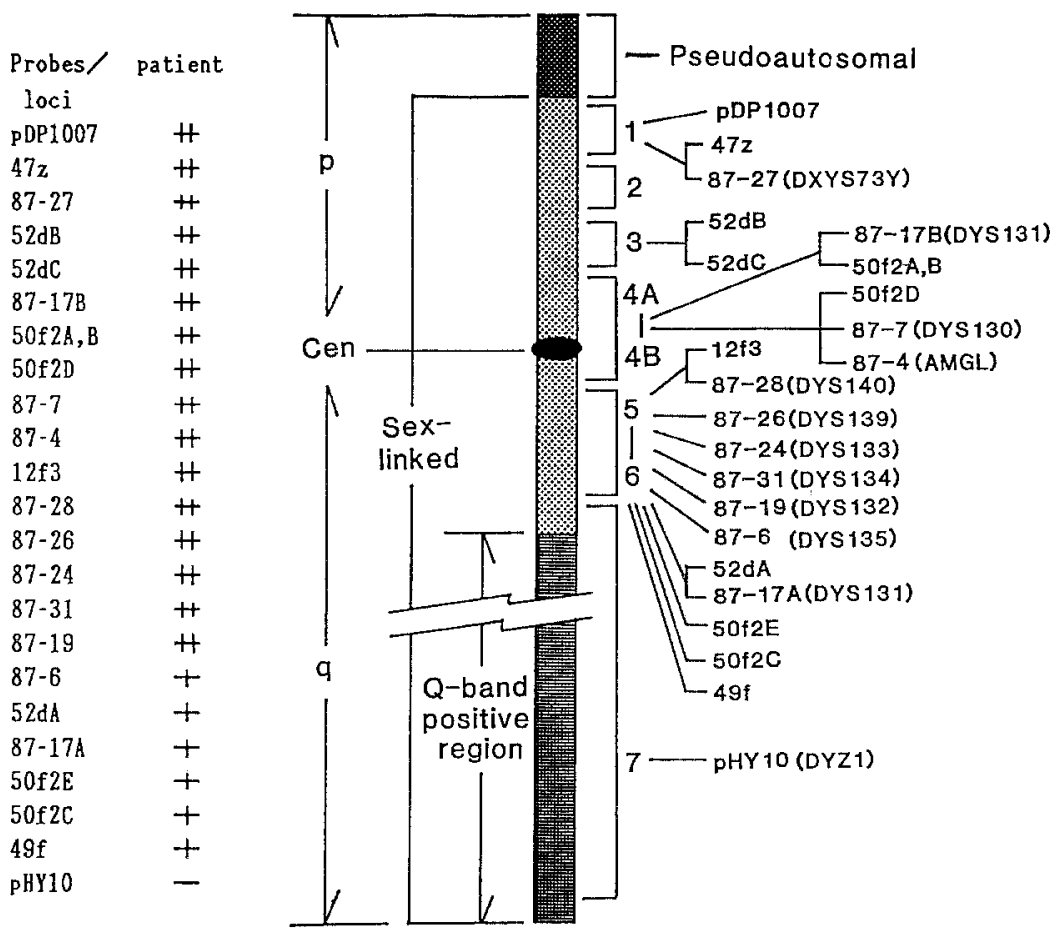

Fig. 3. Summary of DNA analysis. Marker I was positive for all probes between pDP1007 and 87-19. Marker II was positive for all probes from pDP1007 to $49 \mathrm{f}$. Both markers were negative for pHY10. ++ indicates the presence of a normal or slightly reduced signal compared with the normal control. + indicates a grossly reduced signal. - indicates the absence of any detectable signal. On the right, positions of $\mathrm{Y}$ chromosome loci are shown. 1-7 represent intervals established by Vergnaud et al. (1986). 


\section{DISCUSSION}

In the patient discussed here, chromosome analysis revealed two different marker chromosomes, a small ring and another which could be a dicentric chromosome. Both marker chromosomes were Q-band negative.

The results of DNA analysis using $17 \mathrm{Y}$-specific DNA probes revealed that both of the marker chromosomes consisted of parts of the Y chromosome. Furthermore, the detected loci showed different signal intensities when hybridized with patient DNA depending on their position on the long arm. Sixteen probes from pDP1007 to 87-19 showed only slightly decreased hybridization signals in agreement with the presence of mar $I$ in 23 of 31 mitotic spreads. The remaining six probes revealed much decreased signals. These findings are in agreement with the presence of mar II in three of 31 mitotic spreads. If marker II had a Yq- structure, it might have been difficult to detect by Southern-blot analysis. Its dicentric nature doubled its copy number in the genome and presumably enabled its detection.

The patient's clinical features are those of unilateral gonadal dysgenesis and are in agreement with finding that both markers are structurally abnormal Y chromosomes.

Acknowledgments This work is supported in part by grants from the Ministry of Health and Welfare and from the Ministry of Education, Science and Culture of Japan.

The authors are grateful to Dr. Sarah B. England for going over the manuscript.

\section{REFERENCES}

Maniatis, T., Fritsch, E.F. and Sambrook, J. 1982. Molecular Cloning. A Laboratory Manual, Cold Spring Harbor Lab., New York.

Nakahori, Y., Mitani, K., Yamada, M. and Nakagome, Y. 1986. A human Y-chromosome specific repeated DNA family (DYZ1) consists of tandem array of pentanucleotides. Nucleic Acids Res. 14: 7569-7580.

Nakahori, Y., Yamada, M. and Nakagome, Y. 1989. Very low rate Y-chromosome mosaicism (1:5400) detectable by a novel probe enzyme combination. Jpn. J. Human Genet. 34: 203-208.

Nakahori, Y., Tamura, T., Nagafuchi, S., Fujieda, K., Minowada, S., Fukutani, K., Fuse, H., Hayashi, K., Kuroki, Y., Fukushima, Y., Agematsu, K., Kuno, T., Kaneko, S., Yamada, K., Kitagawa, T., Nonomura, M., Fukuda, S., Kusano, M., Onigata, S., Hibi, I. and Nakagome, Y. 1991. Molecular cloning and mapping of ten new probes on the human $Y$ chromosome. Genomics 9: 765-769.

Page, D.C., Mosher, R., Shimpson, E.M., Fisher, E.M.C., Mardon, G., Pollack, J., McGillivary, B., de la Chapelle, A. and Brown, L.G. 1987. The sex determining region of the human Y chromosome encodes a finger protein. Cell 51: 1091-1104.

Vergnaud, G., Page, D.C., Simmler, M.C., Brown, L., Rouyer, F., Novel, B., Botstein, D., de la Chapelle, A. and Weissenbach, J. 1986. A deletion map of the human $Y$ chromosome based on DNA hybridization. Am. J. Hum. Genet. 38: 109-124. 